Archived version from NCDOCKS Institutional Repository http://libres.uncg.edu/ir/asu/

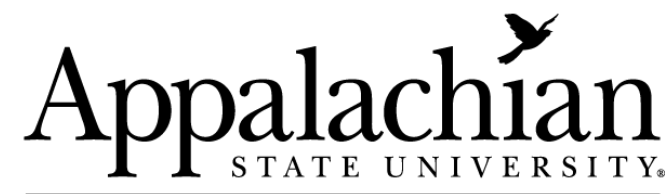

B O O N E, NORT H C A R O L I N A

\section{Complementary And Alternative Medicine: The Mozart Effect On Childhood Epilepsy- A Systematic Review}

\author{
By: Dana E. Brackney and Jessica L. Brooks
}

\begin{abstract}
This systematic review examines the effectiveness of Mozart's music in decreasing seizures in children with epilepsy (Mozart Effect) using the Johns Hopkins Nursing Evidence-Based Practice rating scalea. A search for articles with "Mozart Effect, "child*," and "epilepsy" was conducted in CINAHL Complete, Science Direct, Cochrane, and PubMed databases. Eight studies were selected based on the exclusion and inclusion criteria after removal of duplicates ( $\mathrm{n} 1 / 4$ 17) and others (n 1/4 46). Studies included were English language, peer reviewed, published between April 2010 and February 2017, and available in full text with an abstract. Quasiexperimental studies demonstrate that the Mozart Effect May reduce epileptiform discharges or seizures in children and has potential as an adjunct to medical management of seizure activity or alone when medication or surgery is not accepted. A causal relationship between the music of Mozart and decreased seizure activity has yet to be demonstrated.
\end{abstract}

Brackney, D. E., \& Brooks, J. L. (2018). Complementary and Alternative Medicine: The Mozart Effect on Childhood Epilepsy-A Systematic Review. The Journal of School Nursing, 34(1), 28-37. https:// doi.org/10.1177/1059840517740940. Publisher version of record available at: https://journals.sagepub.com/ doi/full/10.1177/1059840517740940 


\title{
Complementary and Alternative Medicine: The Mozart Effect on Childhood Epilepsy- A Systematic Review
}

\author{
Dana E. Brackney, PhD, RN, CNS, CDE, BC-ADM', \\ and Jessica L. Brooks, BSN, RN ${ }^{2}$
}

\begin{abstract}
This systematic review examines the effectiveness of Mozart's music in decreasing seizures in children with epilepsy (Mozart Effect) using the Johns Hopkins Nursing Evidence-Based Practice rating scale ${ }^{\odot}$. A search for articles with "Mozart Effect, "child*," and "epilepsy" was conducted in CINAHL Complete, Science Direct, Cochrane, and PubMed databases. Eight studies were selected based on the exclusion and inclusion criteria after removal of duplicates $(n=17)$ and others $(n=46)$. Studies included were English language, peer reviewed, published between April 2010 and February 20 I7, and available in full text with an abstract. Quasi-experimental studies demonstrate that the Mozart Effect May reduce epileptiform discharges or seizures in children and has potential as an adjunct to medical management of seizure activity or alone when medication or surgery is not accepted. A causal relationship between the music of Mozart and decreased seizure activity has yet to be demonstrated.
\end{abstract}

\section{Keywords}

Mozart Effect, seizures, child*, systematic review, alternative therapies

Epilepsy is among the prevalent childhood conditions that the school nurse encounters. Miller, Coffield, Leroy, and Wallin (2016) calculated the prevalence of epilepsy in school-aged children as $0.69 \%$, with higher rates in Hispanic than in non-Hispanic children $(0.75 \%$ vs. $0.46 \%)$. This translates into a prevalence of 25 students with epilepsy in the average school district of 3,659 students. Adolescents aged 12-18 years had $29 \%$ lower odds of having epilepsy than children aged 0-5 years (Miller, Coffield, Leroy, \& Wallin, 2016 , p. 361). Seizure activity is a very disruptive symptom for those living with epilepsy. The type of seizure a child experiences is dependent on the region of the brain involved. Seizure-related brain waveforms are called epileptiform discharges. In addition to occurring during a seizure, they occur inconsistently before and after seizure activity. One of the five people with epilepsy will not have epileptiform discharges even when brain activity is recorded over long periods of time (Werhahn, Hartl, Hamann, Breimhorst, \& Noachtar, 2015). This inconsistency in the appearance of epileptiform discharges complicates the study of epilepsyrelated seizure activity.

Seizures place a child at risk for social isolation, physical injury, or even death. In order to promote safety for children with epilepsy, the National Association of School Nurses and The Epilepsy Foundation developed a training program titled, Managing Students with Seizures (Austin, Kakacek, \& Carr, 2010). This program educates school nurses in how to implement a seizure action plan, how to communicate with others about seizure first aid, and how to locate resources for parents regarding epilepsy management in the school setting. In this way, the school nurse is integral to student safety during a seizure and is involved in seizure prevention and management for students with this prevalent condition.

Many children avoid seizures effectively with antiepileptic drugs. However, these beneficial medications also have less desirable side effects such as dizziness, fatigue, blurred vision, headache, and/or cognitive changes. Antiepileptic drug side effects generally lessen over time and are minimized with gradual dosage increases until a therapeutic level is achieved (French, 2004). Refractory epilepsy is defined as epilepsy, in which antiepileptic drugs are not effective at decreasing seizure frequency to less than once a month despite treatment with medications (National Institute for

\footnotetext{
1 Department of Nursing, Beaver College of Health Sciences, Appalachian State University, Boone, NC, USA

${ }^{2}$ Novant Health, Charlotte, NC, USA

Corresponding Author:

Dana E. Brackney, Department of Nursing, Beaver College of Health Sciences, Appalachian State University, Edwin Duncan Hall, ASU Box 9215I, Boone, NC 28608, USA.

Email: brackneyde@appstate.edu
} 
Table I. JHNEBP Evidence Rating Scales.

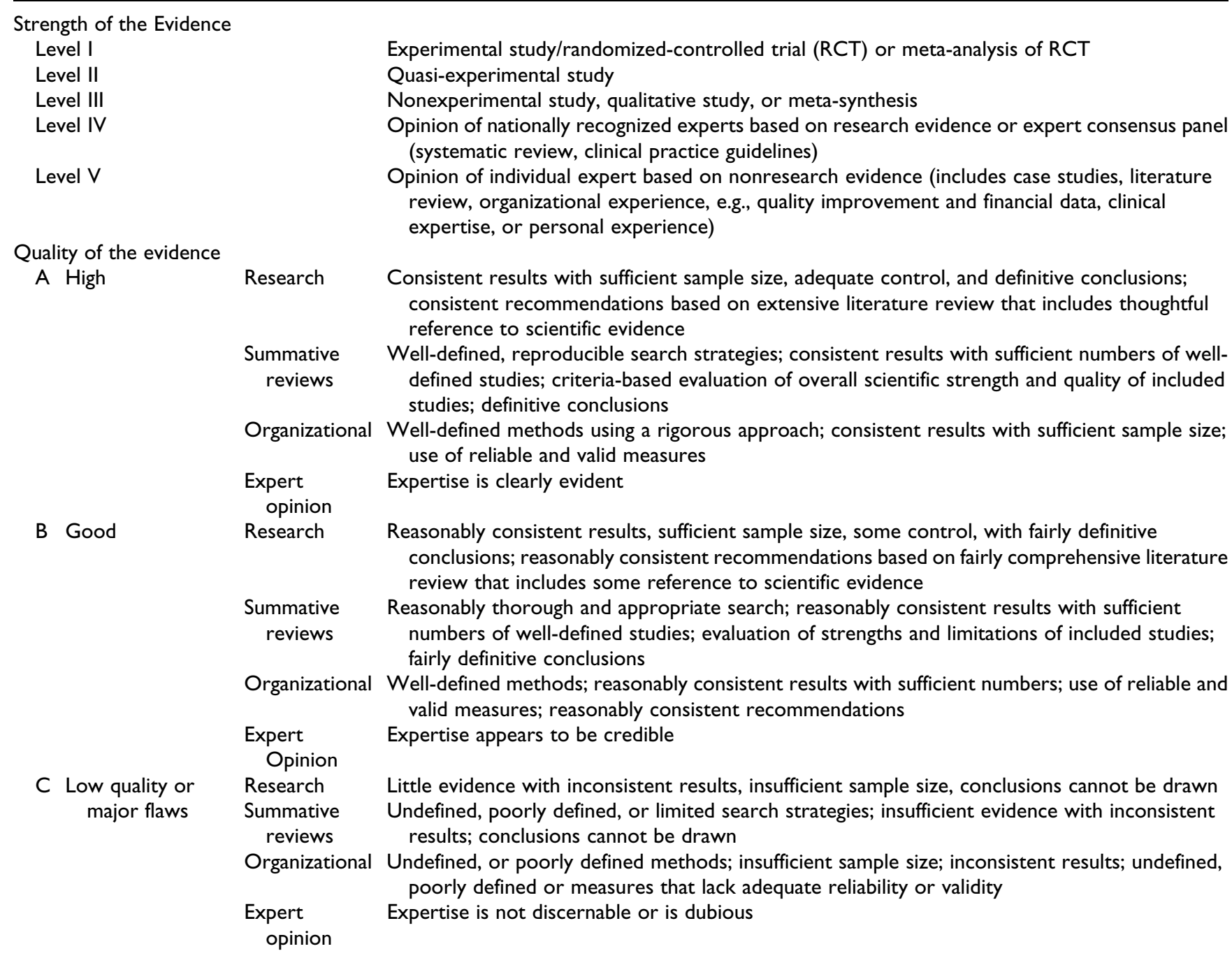

Note. Adapted from Newhouse, Dearholt, Poe, Pugh, and White (2005). ( The Johns Hopkins Hospital/The Johns Hopkins University. A study rated an A would be of high quality, whereas a study rated a $C$ would have major flaws that raise serious questions about the believability of the findings and should be automatically eliminated from consideration. JHNEBP $=$ Johns Hopkins Nursing Evidence-Based Practice.

Health and Care Excellence, 2012). A potential complementary and alternative medicine treatment for seizure prevention in children with epilepsy is music especially Mozart's piano sonatas K. 545 or K. 448.

The use of any form of music to improve neurologic function has been termed the Mozart Effect. Rauscher et al. (1997) popularized the Mozart Effect as a method to improve intellectual or school performance. However, other researchers were unable to replicate these positive cognitive findings and concluded that academic performance is not improved with music listening (Črnčec, Wilson, \& Prior, 2006; Jones \& Zigler, 2002). Currently, there is popular interest in the use of music, specifically Mozart's sonatas, to control epileptic seizures. Social media and reporting in popular press contribute to parental interest in the use of the Mozart Effect in childhood epilepsy despite limited available supportive research. Anecdotally, parents seek alternative therapies due to fear of traditional medical and surgical epilepsy treatments. These concerns make alternative therapies for management of childhood epilepsy attractive to parents. The school nurse can benefit children with epilepsy and their families by becoming informed about the state of the science for this complementary and alternative medicine treatment. The purpose of this systematic review is to examine the effectiveness of Mozart's music in decreasing seizures in children with epilepsy (the Mozart Effect) using the Johns Hopkins Nursing Evidence-Based Practice (JHNEBP) rating scale (Table 1, Newhouse, Dearholt, Poe, Pugh, \& White, 2005). The research question was what is the quality of recently published, English language, peer-reviewed studies on the effect of Mozart's music on seizure 


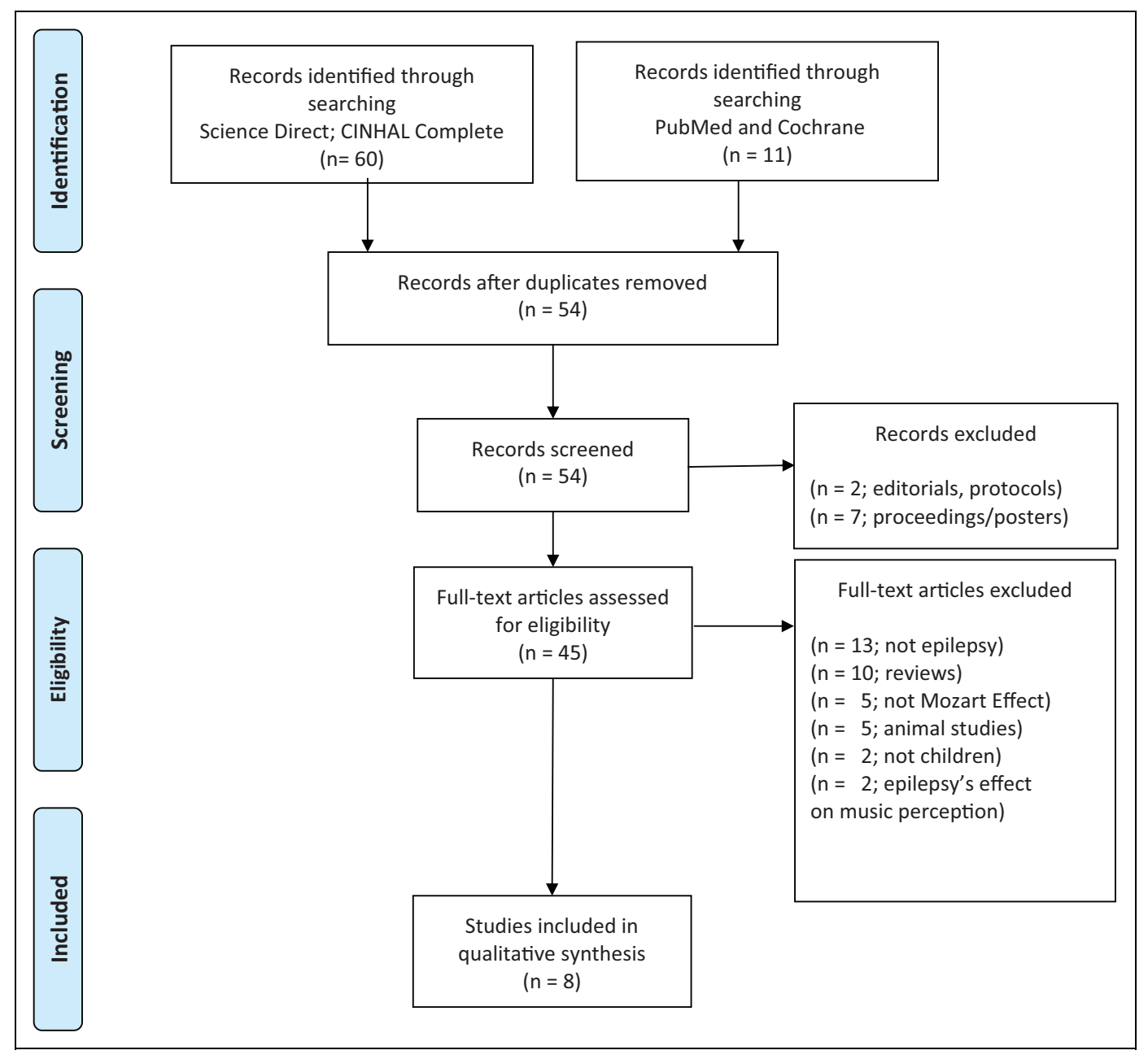

Figure I. Study selection process.

frequency and/or epileptiform discharges on children with epilepsy?

\section{Method}

Identifying a population, an intervention, a comparison, and an outcome is one systematic approach to defining a research question and evaluating the research available to guide evidence-based practice (Houser, 2015). In this systematic review, the population is children with epilepsy. The Mozart Effect is the intervention being evaluated. When available, comparisons are made between studies of the Mozart Effect and other epilepsy treatments. The outcome measure is the frequency of epileptic seizures and/or epileptiform discharges.

A systematic review process guided the selection and evaluation of available evidence on the effectiveness of Mozart's music in decreasing seizures in children with epilepsy. Researchers searched in four electronic databases including PubMed, Science Direct, CINAHL Complete, and Cochrane for published studies. The inclusion criteria included original peer-reviewed English language studies of the Mozart Effect on childhood epilepsy that were published between April 2010 and February 2017 with full text and abstract available. Each search included combinations of at least two of the following search terms: "epilepsy," "child*," and "Mozart Effect." This search strategy resulted in a total of 71 articles. Researchers reviewed each abstract for inclusion and identified eight articles that met the inclusion criteria (Figure 1). Two researchers independently applied the rating scale (Table 1) to evaluate each of the eight remaining articles. Each article was discussed until achieving a unanimous agreement on the rating.

\section{Results}

The eight articles selected for this systematic review all examined the Mozart Effect and childhood epilepsy (Table 2). Seven of the eight published reports were from the same research group in Taiwan. The sample in these seven studies was evaluated by comparing the descriptions 
Table 2. Characteristics and Evaluation of Level I and II articles with JHNEBP Rating Scale.

\begin{tabular}{|c|c|c|c|c|c|c|}
\hline $\begin{array}{l}\text { Article } \\
\text { Lin, Lee, } \\
\text { et al. } \\
(2014)\end{array}$ & $\begin{array}{c}\begin{array}{c}\text { Sample } \\
\text { Size }\end{array} \\
48\end{array}$ & $\begin{array}{l}\text { Sample } \\
\text { Characteristics } \\
25 \text { male; } 2 \text { I female } \\
\text { Age } 8 \text { years/7 } \\
\text { months to I } 3 \\
\text { years } \\
\text { First unprovoked } \\
\text { seizure with } \\
\text { epileptiform } \\
\text { discharges } \\
\text { No antiepileptic } \\
\text { medications } \\
\text { prescribed until } \\
\text { second seizure }\end{array}$ & $\begin{array}{l}\text { Intervention } \\
\text { Treatment group listened } \\
\text { to Mozart K.448 daily } \\
\text { before bedtime for at } \\
\text { least } 6 \text { months } \\
\text { Control group had usual } \\
\text { care }\end{array}$ & $\begin{array}{l}\text { Conclusion } \\
\text { Significant decreases in } \\
\text { epileptiform discharges } \\
\text { after I, 2, and } 6 \text { months } \\
\text { of listening to Mozart } \\
\text { K.448 compared with } \\
\text { EEGs before listening to } \\
\text { music. } \\
\text { The seizure } \\
\text { reoccurrence rate of the } \\
\text { treatment group } 8 / 22 \\
\text { was significantly lower } \\
\text { than the control group } \\
\text { I8/24. }\end{array}$ & \multicolumn{2}{|c|}{$\frac{\text { JHEBP Rating Scale }}{\text { Strength }}$} \\
\hline $\begin{array}{l}\text { Lin, Lee, Wu, } \\
\text { et al. } \\
\quad(20 \mathrm{II})\end{array}$ & 18 & $\begin{array}{l}8 \text { male; I0 female } \\
\text { Age } 7 \text { months to } \\
\text { I4 years } \\
\text { II IQ } \geq 70 ; 7 \mathrm{IQ}< \\
70 \\
\text { Epilepsy diagnosis } \\
\text { and } \\
\text { clinically well } \\
\text { controlled with } \\
\text { antiepileptic drugs } \\
\text { for } 6 \text { months with } \\
\text { prominent } \\
\text { epileptiform } \\
\text { discharges }\end{array}$ & $\begin{array}{l}\text { Listened to Mozart K.448 } \\
\text { for } 8 \text { min once a day } \\
\text { before bedtime for } \\
6 \text { months }\end{array}$ & $\begin{array}{l}\text { Prior to music exposure, } \\
\text { there was no significant } \\
\text { change in epileptiform } \\
\text { discharges after more } \\
\text { than } 6 \text { months of } \\
\text { antiepileptic drug } \\
\text { treatment. } \\
\text { Significant decreases in } \\
\text { epileptiform discharges } \\
\text { were found after I, 2, } \\
\text { and } 6 \text { months of listening } \\
\text { to Mozart K.448 when } \\
\text { compared with EEGs } \\
\text { before listening to music } \\
\text { Less effect on children } \\
\text { with lower IQ. }\end{array}$ & $\begin{array}{l}\text { Level II } \\
\text { Quasi- } \\
\text { experimental } \\
\text { One group } \\
\text { Pretest/ } \\
\text { posttest } \\
\text { No control } \\
\text { No } \\
\text { randomization }\end{array}$ & $\begin{array}{l}\text { Quality } \\
\text { Good }\end{array}$ \\
\hline $\begin{array}{l}\text { Lin, Lee, } \\
\text { Wang, } \\
\text { et al. } \\
(2011)\end{array}$ & II & $\begin{array}{l}6 \text { male; } 5 \text { female } \\
\text { Age } 2 \text { years } / 9 \\
\text { months to I4 } \\
\text { years } \\
2 \text { IQ } \geq 70 ; 9 \text { IQ < } \\
70 \\
\text { Diagnosed with } \\
\text { refractory } \\
\text { epilepsy > I year. } \\
\text { Prescribed two or } \\
\text { more antiepileptic } \\
\text { drugs }\end{array}$ & $\begin{array}{l}\text { Listened to Mozart K.448 } \\
\text { for } 8 \text { min once a day } \\
\text { before bedtime for } \\
6 \text { months } \\
\text { Children remained on } \\
\text { the same medications } \\
\text { during the 6-month } \\
\text { period }\end{array}$ & $\begin{array}{l}\text { Eight of I I patients were } \\
\text { seizure free }(n=2) \text { or } \\
\text { had very good responses } \\
\text { ( } n=6) \text { after } 6 \text { months of } \\
\text { listening to Mozart } \\
\text { K.448. } \\
72.7 \% \text { of patients } \\
\text { became seizure free or } \\
\text { had a very good } \\
\text { response to listening to } \\
\text { Mozart K.448. }\end{array}$ & $\begin{array}{l}\text { Level II } \\
\text { Quasi- } \\
\text { experimental } \\
\text { One group } \\
\text { Pretest/ } \\
\text { posttest } \\
\text { No control } \\
\text { No } \\
\text { randomization }\end{array}$ & $\begin{array}{l}\text { Quality } \\
\text { Low } \\
\text { Small } \\
\text { sample size } \\
\text { with uneven } \\
\text { results }\end{array}$ \\
\hline
\end{tabular}


Table 2. (continued)

\begin{tabular}{|c|c|c|c|c|c|c|}
\hline \multirow{3}{*}{$\begin{array}{l}\text { Article } \\
\text { Lin, Lee, } \\
\text { Wei, et al. } \\
(2012)\end{array}$} & \multirow{3}{*}{$\begin{array}{c}\begin{array}{c}\text { Sample } \\
\text { Size }\end{array} \\
39\end{array}$} & \multirow{2}{*}{$\begin{array}{l}\text { Sample } \\
\text { Characteristics }\end{array}$} & \multirow[b]{2}{*}{ Intervention } & \multirow[b]{2}{*}{ Conclusion } & \multicolumn{2}{|c|}{ JHEBP Rating Scale } \\
\hline & & & & & \multicolumn{2}{|c|}{ Strength } \\
\hline & & $\begin{array}{l}19 \text { male; } 20 \text { female } \\
\text { Age } 2 \text { years } / 9 \\
\text { months to } 17 \\
\text { years } \\
32 \mathrm{IQ} \geq 70 ; 5 \mathrm{IQ}< \\
70 \\
\text { (two } \\
\text { undetermined) } \\
\text { Diagnosed with } \\
\text { epilepsy }\end{array}$ & $\begin{array}{l}\text { Children received EEG } \\
\text { examinations before, } \\
\text { during, and after listening } \\
\text { to Mozart K.448 and } \\
\text { K.545 one week apart } \\
\text { The frequencies of } \\
\text { epileptiform discharges } \\
\text { were compared }\end{array}$ & $\begin{array}{l}\text { There was a significant } \\
\text { decrease in the } \\
\text { frequency of } \\
\text { epileptiform discharges } \\
\text { during and right after } \\
\text { listening to Mozart } \\
\text { K.448 and K.545. } \\
\text { Discharges reduced by } \\
35.7 \% \pm 32.7 \% \text { during } \\
\text { Mozart K.448 and } 30.3 \% \\
\pm 44.4 \% \text { after Mozart } \\
\text { K.448; and } 34.0 \% \pm \\
39.5 \% \text { during Mozart } \\
\text { K.545 and } 31.8 \pm 39.2 \% \\
\text { after Mozart K.545. } \\
\text { Listening to either } \\
\text { sonata can be beneficial } \\
\text { for children with } \\
\text { epilepsy. }\end{array}$ & $\begin{array}{l}\text { Level II } \\
\text { Quasi- } \\
\text { experimental } \\
\text { One group } \\
\text { Pretest/ } \\
\text { posttest } \\
\text { No control } \\
\text { No } \\
\text { randomization }\end{array}$ & $\begin{array}{l}\text { Quality } \\
\text { Good } \\
\text { Small } \\
\text { sample size } \\
\text { Reasonable } \\
\text { expert } \\
\text { opinion }\end{array}$ \\
\hline $\begin{array}{l}\text { Lin et al. } \\
(2013)\end{array}$ & 64 & $\begin{array}{l}\text { 3I male; } 33 \text { female } \\
\text { Age } 2 \text { years/II } \\
\text { months to I5 } \\
\text { years } \\
54 \text { IQ } \geq 70 ; 9 \text { IQ < } \\
70 \\
\text { (one } \\
\text { undetermined) } \\
\text { Diagnosed with } \\
\text { epilepsy }\end{array}$ & $\begin{array}{l}\text { Participants could chose to } \\
\text { listen to either Mozart } \\
\text { K.448 ( } 8 \text { min } 22 \mathrm{~s}) \text { or } \\
\text { Mozart K.545 ( } 9 \text { min } 7 \mathrm{~s}) \\
\text { Forty-one children } \\
\text { listened to K.448 and } 23 \\
\text { children listened to } \\
\text { K.545 } \\
\text { EKG data were used as a } \\
\text { measure of } \\
\text { parasympathetic activity }\end{array}$ & $\begin{array}{l}\text { Most participants ( } 90.2 \% \\
\text { and } 82.6 \% \text { during Mozart } \\
\text { K.448 and K.545) } \\
\text { decreased their } \\
\text { epileptiform discharges. } \\
\text { Measured heart rate } \\
\text { variability and } \\
\text { Listening to either } \\
\text { sonata can be beneficial } \\
\text { for children with } \\
\text { epilepsy. }\end{array}$ & $\begin{array}{l}\text { Level II } \\
\text { Quasi- } \\
\text { experimental } \\
\text { One group } \\
\text { Pretest/ } \\
\text { posttest } \\
\text { No control } \\
\text { No } \\
\text { randomization }\end{array}$ & $\begin{array}{l}\text { Quality } \\
\text { Good }\end{array}$ \\
\hline $\begin{array}{l}\text { Lin, Ouyang, } \\
\text { et al. } \\
(2014)\end{array}$ & 19 & $\begin{array}{l}8 \text { male; II female } \\
\text { Age } 4 \text { years } / 2 \\
\text { months to } 12 \\
\text { years } \\
\text { I } 7 \mathrm{IQ} \geq 70 ; 2 \mathrm{IQ}< \\
70 \\
\text { Diagnosed with } \\
\text { epilepsy }\end{array}$ & $\begin{array}{l}\text { Participants listened to } \\
\text { Mozart K.448's first } \\
\text { movement ( } 8 \text { min } 22 \mathrm{~s} \text { ) } \\
\text { EEG examinations were } \\
\text { performed in two parallel } \\
\text { periods in each patient; } \\
\text { before, and while } \\
\text { listening to } \\
\text { EEG data were compared } \\
\text { by qEEG }\end{array}$ & $\begin{array}{l}\text { The qEEG has potential to } \\
\text { predict brain response } \\
\text { even in those without } \\
\text { epileptiform discharges. } \\
\text { Therapeutic } \\
\text { effectiveness of music in } \\
\text { patients with epilepsy } \\
\text { can be confirmed with } \\
\text { the qEEG. }\end{array}$ & $\begin{array}{l}\text { Level II } \\
\text { Quasi- } \\
\text { experimental } \\
\text { One group } \\
\text { Pretest/ } \\
\text { posttest } \\
\text { No control } \\
\text { No } \\
\text { randomization }\end{array}$ & $\begin{array}{l}\text { Quality } \\
\text { Good }\end{array}$ \\
\hline $\begin{array}{l}\text { Coppola, } \\
\text { et al. } \\
(2015)\end{array}$ & II & $\begin{array}{l}7 \text { male; } 4 \text { female } \\
\text { Ages I year/6 } \\
\text { months to } 21 \\
\text { years } \\
\text { Diagnosed with } \\
\text { epilepsy, severe } \\
\text { intellectual } \\
\text { disability, and } \\
\text { Cerebral Palsy } \\
\text { Drug resistant } \\
\text { encephalopathy }\end{array}$ & $\begin{array}{l}\text { Listened to music } 2 \mathrm{hr} \text { a day } \\
\text { for } \mathrm{I} 5 \text { days } \\
\text { Mozart compositions } \\
\text { presented to each } \\
\text { person included } \\
\text { symphonies } 4 \mathrm{I} \text { and } 46, \\
\text { piano concerto } 22(\mathrm{~K} . \\
482) \text {, violin concertos I } \\
\text { and } 4 \text {, and flute concerto } \\
\text { (K. } 3 \text { I4) }\end{array}$ & $\begin{array}{l}\text { Five of the II experienced } \\
\text { more than a } 50 \% \\
\text { reduction in the total } \\
\text { number of seizures after } \\
\text { listening to a set of } \\
\text { Mozart's compositions } \\
\text { or I5 days. } \\
\text { Three of the five } \\
\text { patients had a seizure } \\
\text { reduction of } 75-89 \% \text {. } \\
\text { Two of the five patients } \\
\text { had a reduction of } 50- \\
75 \% \text { in seizure } \\
\text { recurrence. }\end{array}$ & $\begin{array}{l}\text { Level II } \\
\text { Quasi- } \\
\text { experimental } \\
\text { One group } \\
\text { Pretest/ } \\
\text { posttest } \\
\text { No control } \\
\text { No } \\
\text { randomization }\end{array}$ & $\begin{array}{l}\text { Quality } \\
\text { Low } \\
\text { Small } \\
\text { sample size } \\
\text { with uneven } \\
\text { results }\end{array}$ \\
\hline
\end{tabular}

Note. EEG = electroencephalogram; qEEG = quantified electroencephalogram; JHNEBP = Johns Hopkins Nursing Evidence-Based Practice. 
of participants (age, intelligence, seizure location, etc.) and the publication dates of each study. We concluded that the participants were likely unique to each published report. One of these seven reports focused on development of a method to measure the brain's response to music using a quantified electroencephalogram (qEEG) for the measurement of epileptiform discharges. All of the Taiwanese studies used the EEG to measure the Mozart Effect and one also asked a child's responsible adult to record seizure frequency in a diary. Coppola et al.'s study (2015) was unique in that they studied the Mozart Effect on epilepsy in Italian children and adolescents with cerebral palsy. Coppola et al. (2015) include caregiver questionnaires, caregiver diaries, and EEG readings to measure the outcome of the Mozart Effect and draw conclusions.

The JHNEBP rating scale (Table 1, Newhouse et al., 2005) guided the determination of strength of the evidence (level) and quality of the research evidence. There was one Level I study and seven Level II studies (Table 2). Study quality was evaluated based on criteria including research, summative reviews, organization, and expert opinion. Quality decisions are dependent on the study type (study level). For example, a Level I research study must have sufficient sample size to be deemed high quality, but by definition, a Level V case study does not employ a large sample size and would not need a large sample to be considered high quality for its level. Instead, the opinions reported in a Level V study must demonstrate evidence of expertise to be acknowledged as high quality. Six reviewed articles (one randomizedcontrolled trial and five quasi-experimental studies) were judged to be of good quality, and two reviewed articles (quasi-experimental studies) were judged to be of low quality. Summaries of each of the eight reviewed studies are presented here by the strength of the evidence and include a discussion of study characteristics and quality of the evidence.

\section{Level I Study}

Lin, Lee, et al. (2014) studied 48 children who had a first unprovoked seizure but had not yet been prescribed antiepileptic drugs. Children were randomly assigned to a control $(n=24)$ or intervention $(n=24)$ group. Children in the intervention group listened to Mozart's sonata for Two Pianos in D major (K. 448) for 8 min once daily during the 6month trial. EEGs were used to measure the frequency of each child's epileptiform activity at 1,2, and 6 months. Seizure reoccurrence rate was $8 / 22$ for the intervention group and 18/24 for the control group. At 6 months, a significantly higher seizure reoccurrence rate in the control group $(58.3 \%)$ versus intervention $(22.7 \%)$ was reported. Children treated with Mozart K.448 once daily had reduced seizure reoccurrence. After 1, 2, and 6 months of music listening, children had a $70-80 \%$ reduction in epileptiform discharges.
Overall, Lin, Lee, et al. (2014) demonstrated that Mozart's music decreases epileptiform discharges and seizure reoccurrence in children. This study was a Level I randomized control trial. Researchers clearly stated inclusion and exclusion criteria. There was adequate control for variables. Of concern is that the research report includes discussion of the Rauscher et al.'s (1997) study that once replicated did not support the use of the Mozart Effect for intellectual enhancement (Jones \& Zigler, 2002). However, Lin, Lee, et al. (2014) do provide expert opinion related to possible mechanisms for the effectiveness of the intervention including music's ability to increase parasympathetic tone in children with epilepsy and improve their midbrain dopamine levels.

The study is limited with a small sample size. The quality of the evidence is good, but due to a smaller sample size, caution should be used in accepting a causal relationship between the Mozart Effect and the reduction in epileptic discharges until these findings are replicated in larger studies.

\section{Level II Studies}

Coppola et al. (2015) studied 11 children $(n=5)$ and adolescents $(n=5)$ with refractory epilepsy (males $=7$, females $=4$ ) from the ages of 1.5-21 years old. In addition to epilepsy, all of the participants had severe cerebral palsy with intellectual disabilities. Researchers investigated whether or not listening to Mozart's music for $2 \mathrm{hr}$ a day for 15 consecutive days would lower their seizure activity. A questionnaire completed by the student's caregiver was used to measure seizure activity prior to music listening. An EEG was taken at baseline and following the music listening. A participant's caregiver recorded seizure frequency in a diary throughout the 15-day intervention period. Participants listened to different musical selections including Mozart's symphonies 41 and 36, piano concerto 22 (K. 482), flute concerto (K. 314), and violin concertos 1 and 4 modified by an electronic ear to deliver the music at a higher frequency using the Tomatis $\mathbb{R}$ method.

Tomatis $(\mathbb{B}$ method devices, such as the electronic ear, are designed to create a contrast in sound perception. Inner ear muscles contract and relax in response to sound. The ear's sudden transition from lower frequency (passive) to higher frequencies (active) causes the muscle movement. The Tomatis $(\mathbb{B}$ method is most known as an alternative therapy for learning disabilities (http://www.tomatis.com/en/toma tis-method/its-function.html).

Coppola et al. (2015) reported that three participants experienced seizure reduction of $75-89 \%$, and two others had a seizure reduction of $50-75 \%$ following the 15-day period of music listening. Although not all participants' seizures were reduced during this study, all of the participants displayed an improvement in their behavior. Unlike other studies in this review, the researchers recommended the use 
of higher frequency harmonics with the dual diagnoses of cerebral palsy and epilepsy. This article is a Level II, onegroup, quasi-experimental design without control or random assignment. Reasonable expert opinion is provided, but with inconsistent results, the study was judged to be of low quality.

Measurement of seizure activity is challenging, and the relationship between epileptiform discharges and seizure activity is controversial (Turner, 2004). Lin, Ouyang, Chiang, Wu, and Yang (2014) reported that reliability of EEG readings to identify epilepsy is poor with a high percentage of false negatives. A single 20 min of EEG monitoring reveals abnormalities in as few as $30-55 \%$ of people with epilepsy. Performing a repeated EEG study can confirm the epilepsy diagnosis in up to $77 \%$ of people with epilepsy. However, 30-50\% of people with epilepsy do not demonstrate any change in the EEG readings. Lin, Ouyang, et al. (2014) conducted a study with 19 Taiwanese children (male $=8$, female $=11$ ) diagnosed with epilepsy. They used computer-assisted qEEG segments to measure the effect of music on children with epilepsy. The qEEG segments were obtained from each child once before and once while listening to Mozart K.448's first movement. Researchers categorized each qEEG segment into one of the two groups: effective or ineffective. The effective group contained children with a $25 \%$ reduction in epileptiform activity with music. The ineffective group contained children with a less than $5 \%$ reduction rate in epileptiform activity. The computer program analyzed the EEG readings on several parameters. Two parameters were found to be most predictive. The researchers concluded that the qEEG was a useful tool for detecting epileptiform discharges in children, and researchers saw promise in its use as a more reliable measure $(\alpha=.95)$. This article was a good Level II quasiexperimental study with a small sample size, without controls or random assignment. The researchers had reasonably consistent results, consistent literature review, and discussion related to scientific evidence.

Lin et al. (2013) studied the epileptiform discharges of 64 children with epilepsy aged 2 years 11 months to 15 years 4 months. Standard EEG measures were obtained continuously before, during, and after listing to Mozart K. 448 or K. 545. The children chose to listen to either K. 448 for 8 $\min 22 \mathrm{~s}$ or K. 545 for $9 \min 7 \mathrm{~s}$. Each child received daytime musical stimuli in a state of wakefulness. Forty-one children listened to Mozart K.448 and 23 children listened to Mozart K.545. Most children (90.2\% during Mozart K.448 and $82.6 \%$ during Mozart K.545) had decreased epileptiform discharges when listening to either piece. Epileptiform discharges were significantly reduced in children with generalized seizures and less effective with occipital seizures. The authors discuss improved parasympathetic tone as a possible mechanism for seizure reduction with music. This onegroup, pretest-posttest, quasi-experimental Level II study was judged to be of good quality. The study lacked randomization and control. The introduction included studies that have been refuted. However, scientific support for the intervention's mechanism of action was included, and consistent findings were reported.

Lin et al. (2012) examined the efficacy of Mozart K. 448 and Mozart K.545. Using the EEG readings, they studied 39 Taiwanese children $($ male $=19$, female $=20$ ) with epilepsy. They measured epileptiform discharges before, during, and after listening to Mozart K. 448 for 8 min $22 \mathrm{~s}$ and K. 545 for $9 \min 7 \mathrm{~s}$. They then repeated the study again 1 week later. They compared the frequencies of epileptiform discharges and reported that most children $(84.6 \%$ during K. 448 and $82.1 \%$ during K. 545) demonstrated decreased interictal discharge frequencies when listening to either piece of music. Children with generalized epilepsy had the best response followed by those with focal seizures. In contrast, those with occipital discharges had an increase in interictal discharges. Researchers concluded that listening to Mozart K. 448 or K. 545 can decrease the epileptiform discharges in children with epilepsy. This study was a one-group, repeat measures, quasi-experimental design without control or randomization. Both its consistent findings and the reasonable scientific evidence related to the mechanism of action for the effective intervention support this Level II study's JHNEBP designation of good quality.

Lin, Lee, Wang, et al. (2011) conducted a study of 11 children with refractory epilepsy over 6 months. Two of the 11 children had a normal IQ measured with the Wechsler Preschool and Primary Scale of Intelligence III. Each child had experienced more than one seizure per month during the preceding year despite taking one or two antiepileptic medications. The child's responsible adult received a diary to record the child's seizure frequency over the year for 6 months prior to music exposure and for 6 months during music exposure. The children listened to Mozart K.448 once a day before bedtime for 6 months. Eight of the 11 children were seizure free $(n=2)$ or had a $50-98 \%(n=6)$ reduction in seizure frequency after 6 months of listening to Mozart K.448 for $45 \mathrm{~min}$ daily. The seizure activity of the other three children had less than a $50 \%$ reduction $(n=1)$, no effect $(n=1)$, or was worse than baseline $(n=1)$. Seizure activity did not differ based on IQ. Children with generalized seizures benefited more than those with focal seizures. This Level II quasi-experimental study employed a pretest/ posttest design of low quality due to its small sample size and uneven results.

Lin, Lee, Wu, et al. (2011) conducted a study of 18 children with at least a 6 month history of well-controlled epilepsy on antiepileptic drugs. These children listened to Mozart K.448 over a period of 6 months for 8 min once daily at bedtime. Researchers monitored brain activity with EEG and compared epileptiform discharges before and after 1,2 , and 6 months of listening to Mozart K.448. They reported that the epileptiform discharges in children with well-controlled epilepsy were reduced during and after 
listening to Mozart K.448. Of note, children with occipital epileptiform discharges had a modest reduction, while there was a significant decrease in seizure activity for children with epileptiform discharges in other regions of the brain. Also, children with lower intelligence did not have as significant a decrease in seizures as the children with normal intelligence experienced. Gender and age did not demonstrate an influence on the frequency of epileptiform discharges in the children. In addition, the discharges continued to decrease over time indicating a dose/time interaction. This article was a one-group, pretest-posttest, Level II quasi-experimental study. Although the introduction includes studies that are no longer supported, the study had findings consistent with other scientific evidence and presented scientific theory to support the intervention's mechanism of action. The study was judged to be of good quality despite a small sample size and lack of control.

Lin et al. (2010) examined the effect of Mozart's Sonata for two pianos in D major (K.448) on seizure foci in 58 children and adolescents with epilepsy. The children (male $=30$, female $=28$ ) were between the ages of 1 year and 19 years 8 months. The participants listened (at 60-70 dB) to piano K.448 for 8 min and had EEG measurements obtained before, during, and after listening. Forty-seven of the 58 children showed a significant decrease in epileptiform discharges while exposed to K.448. Eleven of the 48 were exposed to string K.448 a week later. Lin et al. reported that interictal discharges were reduced in $81 \%$ of the children who listened to piano K.448. Although two kinds of music had the same melody, piano K.448 (low harmonics) and string K.448 (high harmonics) differed in their harmonics. Interestingly, the lower harmonics found in piano K.448 better decrease seizure activity compared with the higher harmonics found in string K.448. This study is quasiexperimental and explores the relationships between two different variables (high and low harmonics with EEG changes). It does not include randomization or control. It is of good quality due to its consistent results, welldefined methods, and scientific discussion.

\section{Discussion}

Music may be a useful tool to decrease seizure activity in children. A systematic review of available evidence was performed to evaluate the level and quality of evidence related to the Mozart Effect on childhood epilepsy. The evidence for the efficacy of the Mozart Effect on seizure activity in children is promising but not conclusive. All of the selected studies had music listening as an independent variable and seizure and/or epileptiform discharges as the dependent variable. Lin, Ouyang, et al. (2014) studied the validity of the qEEG as a measure of seizure activity. The remaining studies examined the outcome measure in the context of other characteristics of the child and/or characteristics of the intervention. The child's characteristics included child's seizure control (refractory or wellcontrolled epilepsy), child's seizure location (focal, generalized, or occipital), gender (male or female), disease conditions (epilepsy with cerebral palsy or epilepsy alone), and intelligence (normal or low). Characteristics of the intervention studied included music's harmonics (high or low), the sonata (K. 545 or K. 448), duration of music listening, and timing (daytime or bedtime).

\section{Strengths}

Strengths of the studies in this review include that they have generally been consistent in their findings. All have demonstrated a reduction of epileptiform discharges in children who have epileptiform discharges to measure. The authors propose several theoretical mechanisms of action for the Mozart Effect. These include increasing dopamine in neurotransmitter pathways, increase in parasympathetic tone, and sensorimotor circuits mediated by mirror neurons. The authors provided detail about participant characteristics, the music listening intervention, data analysis, and results. Although there is no cure for epilepsy, the Mozart Effect can augment medical epilepsy treatment and possibly decrease the medication dose needed to prevent seizure activity. The evidence from this review adequately supports that the Mozart Effect did not cause any adverse effects in children with epilepsy. The Mozart Effect is an accessible alternative treatment for people who do not accept the risks of surgical epilepsy treatment or who have epilepsy refractory to medications.

\section{Limitations}

A majority (7/8) of the studies of this complementary and alternative intervention under review have been performed by one research group. Only one of the studies was a random-controlled trial (Lin, Lee, et al., 2014). The researchers identified a causal relationship between the Mozart Effect and seizure reduction, but the study included a small sample size and has not been replicated. Most studies were quasi-experimental with a one-group, pretest-posttest design. This design can explore cause and effect; however, the findings of these studies are also limited without their replication by other research groups. Quasi-experimental (Level II) studies have reported that listening to Mozart's K. 448 or K. 545 reduces epileptiform discharges. The studies could be considered observational in nature and again do not provide causal evidence of the effect of music listening on seizure frequency. The majority of the research was completed with Asian children, and racial variations were not discussed or studied. Repeated studies of the Mozart Effect on spatial relationships and intelligence have not demonstrated its effectiveness for improving cognitive outcomes, and yet reference to these studies was made in several of the articles under review (Črnčec et al., 2006; Lin et al., 2013; Lin, Lee, et al., 2014). 


\section{Implications for the School Nurse}

The school nurse may suggest that parents speak with their health-care provider about adding 8-10 min of listening to the lower harmonic Mozart's K. 448 or K. 545 for piano at bedtime to the seizure management/prevention plan of students of normal intelligence with nonoccipital seizures (Lin et al., 2010). Students with lower intelligence may benefit from adding 45 min of Mozart's K. 448 or K. 545 for string instruments (higher harmonics) at bedtime (Coppola et al., 2015; Lin, Lee, Wang, et al., 2011). There is not adequate evidence to support music listening in place of antiepileptic medications. The school nurse may consider discussing the Mozart Effect as an adjunct to a student's current epilepsy treatment for seizure prevention. Additionally, school nurses may educate parents about the strengths (e.g., consistent reports of reduction in epileptiform discharges in nonoccipital seizures) and limitations (e.g., studies were not repeated by other researchers, small sample size, study design did not include controls) of the research.

Although not a focus of this review, Coppola et al. (2015) reported that caregivers observed improved behavior in children with cerebral palsy and epilepsy during the 15-day study period. Other studies included in this review did not measure or report an improvement in children's behavior. The school nurse could explore use of the Mozart Effect at school with higher harmonics (string instrument) for students with both recurring seizures and cerebral palsy to reduce seizure activity and possibly improve behavior (Coppola et al., 2015). However, the research supporting this recommendation is extremely limited as it is from one brief, uncontrolled study's findings and has yet to be replicated.

\section{Conclusion}

Overall, the Mozart Effect is a safe, alternative, adjunctive treatment for children with epilepsy. Due to the level and quality of studies, its effectiveness has yet to be determined. Future studies of the Mozart Effect would benefit from randomization, control, larger sample size, and inclusion of other populations. In addition, other sonatas or repetitious music with low harmonics could add to our understanding of the effect music has on the management of epilepsy symptoms. Longitudinal studies would be of great interest and benefit.

\section{Authors' Note}

Mark Zrull, Department of Psychology, College of Arts and Sciences, Appalachian State University, contributed to the review of this study as a member of the Honors College.

\section{Declaration of Conflicting Interests}

The author(s) declared no potential conflicts of interest with respect to the research, authorship, and/or publication of this article.

\section{Funding}

The author(s) received no financial support for the research, authorship, and/or publication of this article.

\section{References}

Austin, J. K., Kakacek, J. M., \& Carr, D. (2010). Impact of training program on school nurses' confidence levels in managing and supporting students with epilepsy and seizures. The Journal of School Nursing, 26, 420-429. doi:10.1177/1059840510380206

Coppola, G., Toro, A., Operto, F. F., Ferrarioli, G., Pisano, S., Viggiano, A., \& Verrotti, A. (2015). Mozart's music in children with drug-refractory epileptic encephalopathies. Epilepsy \& Behavior, 50, 18-22. doi:10.1016/j.yebeh.2015.05.038

Črnčec, R., Wilson, S., \& Prior, M. (2006). No evidence for the Mozart effect in children. Music Perception: An Interdisciplinary Journal, 23, 305-318. doi:10.1525/mp.2006.23.4.305

French, J. A., Kanner, A. M., Bautista, J., Abou-Khalil, B., Browne, T., \& Harden, C. L., ... American Epilepsy Society Quality Standards Subcommittee. (2004). Efficacy and tolerability of the new antiepileptic drugs I: Treatment of new onset epilepsy: Report of the Therapeutics and Technology Assessment Subcommittee and Quality Standards Subcommittee of the American Academy of Neurology and the American Epilepsy Society. Neurology, 62, 1252-1260. doi:10.1212/01.WNL. 0000123693.82339.FC

Houser, J. (2015). Nursing research: Reading, using and creating evidence (3rd ed.). Sudbury, MA: Jones and Bartlett.

Jones, S. M., \& Zigler, E. (2002). The Mozart effect: Not learning from history. Applied Developmental Psychology, 23, 355-372.

Lin, L. C., Chiang, C. T., Lee, M. W., Mok, H. K., Yang, Y. H., Wu, H. C., . . Yang, R. C. (2013). Parasympathetic activation is involved in reducing epileptiform discharges when listening to Mozart music. Clinical Neurophysiology, 124, 1528-1535. doi: 10.1016/j.clinph.2013.02.021

Lin, L. C., Lee, W. T., Wang, C. H., Chen, H. L., Wu, H. C., Tsai, C. L., .. Y Yang, R. C. (2011). Mozart K.448 acts as a potential add-on therapy in children with refractory epilepsy. Epilepsy \& Behavior, 20, 490-493. doi:10.1016/j.yebeh.2010.12.044

Lin, L. C., Lee, W. T., Wei, R. C., Mok, H. K., Wu, H. C., Tsai, C. L., \& Yang, R. C. (2012). Mozart K.545 mimics Mozart K.448 in reducing epileptiform discharges in epileptic children. Evidence-Based Complementary and Alternative Medicine. doi:10.1155/2012/607517

Lin, L. C., Lee, W. T., Wei, H. C., Mok, H. K., \& Yang, R. C. (2014). Mozart K.448 listening decreased seizure recurrence and epileptiform discharges in children with first unprovoked seizures: A randomized controlled study. BMC Complementary \& Alternative Medicine, 14. doi:10.1186/1472-6882-14-17

Lin, L. C., Lee, W. T., Wu, H. C., Tsai, C. L., Wei, R. C., Jong, Y. J., \& Yang, R. C. (2010). Mozart K.448 and epileptiform discharges: Effect of ratio of lower to higher harmonics. Epilepsy Research, 89, 238-245. doi:10.1016/j.eplepsyres.2010.01.007

Lin, L. C., Lee, W. T., Wu, H. C., Tsai, C. L, Wei, R. C., Mok, H. K., ... Yang, R. C. (2011). The long-term effect of listening to 
Mozart K.448 decreases epileptiform discharges in children with epilepsy. Epilepsy \& Behavior, 21, 420-424. doi:10. 1016/j.yebeh.2011.05.015

Lin, L. C., Ouyang, C. S., Chiang, C. T., Wu, H. C., \& Yang, R. C. (2014). Early evaluation of the therapeutic effectiveness in children with epilepsy by quantitative EEG: A model of Mozart K. 448 listening-A preliminary study. Epilepsy Research, 108, 1417-1426. doi:10.1016/j.epilepsyres.2014.06.020

Miller, G. F., Coffield, E., Leroy, Z., \& Wallin, T. (2016). Prevalence and costs of five chronic conditions in children. The Journal of School Nursing, 32, 357-364. doi:10.1177/ 1059840516641190

National Institute for Health and Care Excellence. (2012). Epilepsies: Diagnosis and management. CG137. Retrieved from https://www.nice.org.uk/guidance/cg137/resources/epilepsiesdiagnosis-and-management-35109515407813

Newhouse, R., Dearholt, S., Poe, S., Pugh, L. C., \& White, K. (2005). The Johns Hopkins nursing evidence-based practice rating scale. Baltimore, MD: The Johns Hopkins Hospital/The Johns Hopkins University.
Rauscher, F. H., Shaw, G. L., Levine, L. J., Wright, E. L., Dennis, W. R., \& Newcomb, R. L. (1997). Music training causes longterm enhancement of preschool children's spatial-temporal reasoning. Neurological Research, 19, 2-8.

Turner, R. P. (2004). The acute effect of music on interictal epileptiform discharges. Epilepsy and Behavior, 662-668. doi:10.1016/j.yebeh.2004.07.003

Werhahn, K. J., Hartl, E., Hamann, K., Breimhorst, M., \& Noachtar, S. (2015). Latency of interictal epileptiform discharges in long-term EEG recordings in epilepsy patients. Seizure: European Journal of Epilepsy, 29, 20-25. doi:10.1016/j.seizure.2015.03.012

\section{Author Biographies}

Dana E. Brackney, $\mathrm{PhD}, \mathrm{RN}, \mathrm{CNS}, \mathrm{CDE}, \mathrm{BC}-\mathrm{ADM}$, is an assistant professor in the Department of Nursing, Beaver College of Health Sciences, Appalachian State University, Boone, NC, USA.

Jessica L. Brooks, BSN, RN, is a staff nurse at Novant Health, Charlotte, NC, USA. 